\title{
Analyzing Whistleblowing Practices at Higher Secondary School Level in District Mianwali
}

\author{
Najia Jahangir \\ M.Phil Scholar University of Sargodha Sub-Campus Mianwali \\ Muhammad Naeem Tahir \\ M.Phil Scholar University of Sargodha Sub-Campus Mianwali \\ Muhammad Asif Malik \\ M.Phil Scholar University of Sargodha Sub-Campus Mianwali
}

\begin{abstract}
The purpose to conducts this research work was Analyzing Whistleblowing Practices at Higher Secondary School Level in District Mianwali. Whistle blowing is the observation of unlawful and mal-practices by the employee of an organization to people or bodies with misuse of power (Near and Miceli, 1995). All the teaching staff and all the students of Higher Secondary of District Mianwali were constitute the population of the study. The selection of the sample of the study was made by using the multi-stage sampling technique. At first stage, a cluster random sampling was employed to make cluster of population. At second stage, stratified sampling technique was employed to draw the sample from 14 Higher Secondary Schools of District Mianwali; at third stage simple random sampling technique was employed to select 6 Higher Secondary Schools in District Mianwali for the study. The questionnaire was the tool of the study. With the help of questionnaire data were collected. After collection the researches utilized more than one statistical technique for instance percentage, mean scores, SD, t-test, and Correlation for data analysis and tabulating.
\end{abstract}

Keywords: Whistleblowing, Whistleblower, Higher Secondary School.

DOI: $10.7176 / \mathrm{JEP} / 10-1-09$

\section{Background}

There are a couple of tries with characterize whistleblowing, however totally there might be no generally recognized definition. The word whistleblowing begins with the expression 'blow the whistle' which exhibits a development that is specific unlawful on the other hand foul. Whistleblowing will be viewed as those disclosure for information in regards to recognized definitive wrongdoing, should social occasions that need help in a position ought to degrade activity, in that condition if this disclosure might be in the all inclusive community enthusiasm. Efficiency on the other hand success about whistleblowing may challenge with portray clearly thus there is no broad Institutionalization or criteria for this specific thought. Near and Miceli (1995) described "the feasibility for whistleblowing as the degree will which those imperfect on the other hand illegal act (or exclusion) might be finished no not exactly for the most part because of whistleblowing what's more inside a sensible time period.

Whistle blowing passing up requested under two sorts; interior what's more external whistle blowing (Miceli et al 1992). This request may have been in light of the channel will report card to that is the recipient obtaining a report card of wrongdoing done an affiliation. External whistleblowing employs outside channel should report card inadequate then again unlawful sharpens over an affiliation. Those collectors of the information require help hostile to defilement on the other hand regulatory organization offices, expansive correspondences furthermore unique external social events of the affiliation.

A whistleblower will be a person who gives individuals access general then again someone on control in regards to certify deceitful or unlawful activities happening secured close by a lawmaking body division, a state subsidized on the other hand private affiliation or an association. Those asserted offense may an opportunity to be requested for a couple of ways; an infringement of law, direction what's all the more then again an impending danger of the open venture for instance, extortion, prosperity/wellbeing infringement and degradation (Hannigan 2006). Sangweni (2005) distinguishes a few activities that have been attempted in South Africa by government to advance responsibility and battle debasement inside general society area. These incorporate enactment on the Advancement of Access to Data Act and the Secured Divulgence Act. This demonstration plans to shield people from exploitation when they uncover defilement and dishonest rehearsals.

The school is submitted will driving its advantages of the business with validity furthermore uprightness, what's more envisions that the total staff with care for select desires done comprehension for their legally binding duties and the School's procedures what's more techniques. Be that as it may, all affiliations confront the peril for things setting off not right beginning with period should time, on the other hand from asserting unwittingly harboring specific unlawful or misleading conduct. The school assumes that done a number cases 
disillusionments and shock on his/her staff will have the ability to raise at whatever stresses with their line manager, talking will them in individual or setting the issue in making and assuming that they slant toward. They may have the capacity on agree an approach about deciding a stress quick also reasonably.

The head of the school will fix a meeting for that whistleblower similarly as fast likewise feasible on look at their anxiety. They will have adequate documentation unobtrusive components on they will record expansion inconspicuous components on engage those issue to an opportunity to be totally explored. Essentially as a base the of the school will documentation the name of the worker and in addition exhibit if the one of a kind desires to such an extent his/her identity with stay classified, however probable and the method for the stress. Secured close by a couple of circumstances it won't be possible with take care of privacy and the Head of the school ought to exhibit this of the workers. The school must make notes and handle a made once-over judgment out of the stress raised also give those whistleblower by a replica similarly as a little while later similarly as feasible then a while later those get-together. The school will in like manner point on accommodate the "whistleblower" a proof for how it suggests ought to deal with the issue. So it is recommend that to minimize the wrongdoing or illegal activities it is necessary for the head of the schools to conduct a whistle blowing practices and also admired the whistle blowers as well.

\section{REVIEW OF RELATED LITERATURE}

\subsection{Whistleblowing}

There are a couple of tries with characterize whistleblowing, however totally there might be no generally recognized definition. The word whistleblower begins with the expression 'blow the whistle' which exhibits a development that is specific unlawful on the other hand foul. An organization namely as The United State Civic Activity Ralph Nader authored those adage in the timely 1970'sto avoid those negative undercurrents initiate toward the day's end for instance, with the end goal that "witnesses" also "narks" (Brown, Mazurski \& Olsen2008). Lewis \& Uys (2007) announced that whistleblowing will be viewed as those disclosure for information in regards to recognized definitive wrongdoing, should social occasions that need help in a position ought to degrade activity, in that condition if this disclosure might be in the all inclusive community enthusiasm.

\subsection{Conceptual Framework}

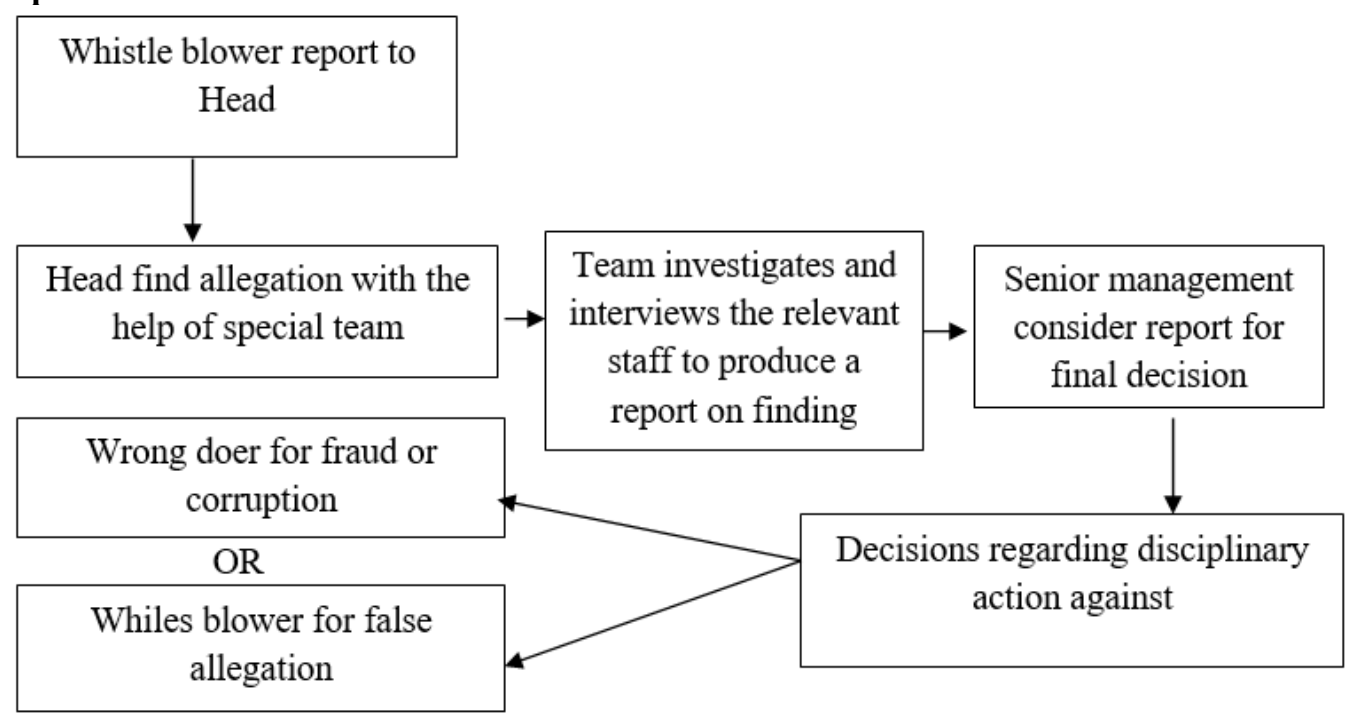

This module represented the whistle blowing practices within the organization like school.

\subsection{Consequences of Whistle-Blowing}

Dellaportas, Gibson, Alagiah, Hutchinson, Leung Furthermore Van Homrigh (2005) alert that same time whistleblowers would saw as legends by those community, inside the association, those whistleblower might be perceived a swindler need's identity unfaithful of the affiliation, furthermore accomplices. Rossouw and Van Vuuren (2004) also agrarian that regardless of the way that legal affirmation will be a lane that could an opportunity to be gone to eventually Tom's scrutinizing the whistleblower, it require an annihilating impact, especially the moment that it realizes losing one's specific occupation.

\subsection{Global Whistle-Blowing Practices}

The Protected Disclosure Act, no. 26 in South Africa went under drive secured nearby February 2001 to ensure whistleblowers, in cooperation in the government and what's more private division. Before this Act, there were 
different endeavors, which consolidate those progression of get should larger part of the information demonstration, furthermore encouraging from asserting hostile to debasement meetings more than 1998 what's more 1999. At the 1999 social affair resolutions were brought with create, give confidence furthermore complete all the whistle blowing parts with secure people from exploitation the moment that they reveal debasement. (Whistle blowing sanctioning no. 26, 2000). Composing around whistleblowing from those emulating enter countries divulge those emulating overall legal shines will limit wrongdoing inside the place of work (Classified and Related Information Disclosure Act 1998; Caslon Analytics guide secrecy and accountability 2000; Hills Governance Centre, 2004; Policy and procedures on whistle-blowing: Definition, 1999; Ravishankar, 2002): • Whistle-blowers Protection Act in Australia (Victoria - 2001; Queensland - 1994); • United Kingdom Public Interest Disclosures Act - 1998; - United States Whistle-blower's Protection Act - 1989; • Japan's Whistleblower Protection Act - 1994; • South Korea's Anti-corruption and Protection Act - 2001; • New Zealand Public Service Whistle-blowing Act - 2000. Distinctive countries that need taken after need help Ghana also Philippines (Hills Governance Center, 2004; Martens and Crowell, 2002).

\subsection{Effectiveness of Whistle Blowing}

Efficiency on the other hand success about whistleblowing may challenge with portray clearly thus there is no broad Institutionalization or criteria for this specific thought. Near and Miceli (1995) described "the feasibility for whistleblowing as the degree will which those imperfect on the other hand illegal act (or exclusion) might be finished no not exactly for the most part because of whistleblowing what's more inside a sensible time period.

\subsection{Internal and External Whistle Blowing}

Whistle blowing passing up requested fewer than two sorts; interior what's more external Whistle blowing (Miceli et al 1992). This request may have been in light of the channel will report card to that is the recipient obtaining a report card of wrongdoing done an affiliation. External whistleblowing employs outside channel should report card inadequate then again unlawful sharpens over an affiliation. Those collectors of the information require help hostile to defilement on the other hand regulatory organization offices, expansive correspondences furthermore unique external social events of the affiliation.

\subsection{The Whistle Blower}

A whistleblower will be a person who gives individuals access general then again someone on control in regards to certify deceitful or unlawful activities happening secured close by a lawmaking body division, a state subsidized on the other hand private affiliation or an association. Those asserted offense may an opportunity to be requested for a couple of ways; an infringement of law, direction what's all the more then again an impending danger of the open venture for instance, extortion, prosperity/wellbeing infringement and degradation (Hannigan 2006).

\subsection{Whistleblowing Practices and Higher Secondary School}

The school is submitted will driving its advantages of the business with validity furthermore uprightness, what's more envisions that the total staff with care for select desires done comprehension for their legally binding duties and the School's procedures what's more techniques. Be that as it may, all affiliations confront the peril for things setting off not right beginning with period should time, on the other hand from asserting unwittingly harboring specific unlawful or misleading conduct. A culture of receptiveness what's greater duty might be key so as should keep such specific conditions happening on the other hand with convey them the moment that they do happen.

\subsubsection{Raising a Whistleblowing Concern}

The school assumes that done a number cases disillusionments and shock on his/her staff will have the ability to raise at whatever stresses with their line manager, talking will them in individual or setting the issue in making and assuming that they slant toward. They may have the capacity on agree an approach about deciding a stress quick also reasonably.

\section{The Head teacher}

\subsubsection{The Governor with Responsibility for Whistleblowing Matters}

The head of the school will fix a meeting for that whistleblower similarly as fast likewise feasible on look at their anxiety. They will have adequate documentation unobtrusive components on they will record expansion inconspicuous components on engage those issue to an opportunity to be totally explored. Essentially as a base the of the school will documentation the name of the worker and in addition exhibit if the one of a kind desires to such an extent his/her identity with stay classified, however probable and the method for the stress. The school must make notes and handle a made once-over judgment out of the stress raised also give those whistleblower by a replica similarly as a little while later similarly as feasible then a while later those get-together. The school will in like manner point on accommodate the "whistleblower" a proof for how it suggests ought to deal with the 
issue.

\subsubsection{Confidentiality}

The school assumes that staff will consider fit with voice whistleblowing stresses straightforwardly under this approach. In any case, if a section for frustrations and shock on his/her staff needs will raise to such an extent or her stress secretly, those one school will attempt with remain with to such an extent or her identity card puzzle thusly likewise it will be could sensibly be relied upon to do along these lines while going with this course of action also method. On it will be important to anyone inquiring about that part for staff's worry with understand the 'whistleblower's character, those school will talk this with those part from asserting disillusionments and shock on his/her staff essential.

\subsubsection{Investigation and Outcome}

Once a piece of frustrations and shock on his/her staff require raised a worry, those one school will do a starting assessment with decide those degree about at whatever examination. That one school will notify all those 'whistleblowers' about the results of its evaluation. On exceptional occasions the one school may name an analyst or participation of specialists including frustrations and shock on his/her staff by pertinent foundation from guaranteeing examinations on the other hand genius learning of the theme.

\subsubsection{Safeguarding}

In the event that a section for dissatisfactions and shock on his/her staff speculates that there will be a completely serious defending issue that they feel that the head will be not taking gravely on the other hand that they think there might be a veritable protecting issue coordinating, including the head they should in the essential event to get in touch with the assigned director.

\section{Methodology of the Study}

\subsection{Research Design}

The descriptive research method was used in the study. The quantitative approach was used to conduct this research work for collecting the views of the respondents with the help of questionnaire. This research work was cross-sectional in term. The intrusion of the researcher was negligible and teachers and students of Higher Secondary School of District Mianwali were the unit of population for this study. The study aim was to analyze whistle blowing practices at higher secondary level in District Mianwali.

\subsection{Population}

The population of the study comprised of all male and female teachers of 14 Higher Secondary Schools of District Mianwali. It also restrained all male and female students of 14 Higher Secondary Schools of District Mianwali.

Table 3.1 Population of the Study

\begin{tabular}{cccccccccc}
\hline Sr. No. & Tehsil & M/S & F/S & Total School & Total & Total M/T & Total F/T & Total M/S & Total F/S \\
\hline 1 & Isa Khel & 2 & 1 & 3 & & & & & \\
2 & Mianwali & 5 & 2 & 7 & \multirow{2}{*}{14} & 216 & 138 & 4197 & 4337 \\
3 & Piplan & 2 & 2 & 4 & & & & &
\end{tabular}

Table 3.1 showed the total population of the study. There were total 14 Higher Secondary Schools of District Mianwali. Table signified that 3 Higher Secondary Schools in Tehsil Isa Khel, 7 Higher Secondary Schools in Tehsil Mianwali and 4 Higher Secondary Schools in Tehsil Piplan.

\subsection{Delimitation of the Study}

This study was delimited to 6 Higher Secondary Schools of District Mianwali. However, there are a total number of 14 Higher Secondary Schools in District Mianwali, in which 9 male Higher Secondary Schools and 5 female Higher Secondary Schools in District Mianwali. Due to shortage of time resources and research constraints; the present study was delimited to only 6 Higher Secondary Schools.

\subsection{Sample \& Sampling Method}

First of all the researcher took the list of Higher Secondary Schools in District Mianwali from the website of School Education Department Government of the Punjab. The next step was the researcher further divided the schools into three Tehsils of District Mianwali, with respect to location of schools. The researcher also alienated male \& female schools. The sample of this study was draw more than one stage commonly called multiple Sampling technique. The sample of the study was selected in three stages. In the first stage made the cluster of three tehsils of District Mianwali trough cluster sampling technique. In the second stage, stratified sampling technique was applied to draw the sample from 14 Higher Secondary Schools of District Mianwali. In the third stage the simple random sampling method was used to select 6 Higher Secondary Schools of District Mianwali. 


\subsection{Sample Size}

A representative sample was taken as follows.

The researcher took 60 male and female teachers of 6 Higher Secondary School of District Mianwali. The researcher also selected 300 male and female students Higher Secondary School of District Mianwali for sample. The total sample of size of the study was 360 .

4Analysis and Interpretation of Data

4.1 Demographical Table

Table 4.1 Demographical Information of Higher Secondary Schools of District Mianwali

\begin{tabular}{|c|c|c|}
\hline Variables & Frequency & Percent \\
\hline \multicolumn{3}{|c|}{ Schools } \\
\hline Govt. Girls Higher Secondary School Kammar Mushar & 51 & 15.7 \\
\hline Government Higher Secondary School Tabbi Sar & 53 & 16.3 \\
\hline Govt. Girls Higher Secondary School Dhurnaka & 57 & 17.5 \\
\hline Govt. Higher Secondary School Wan Bhachran & 55 & 16.9 \\
\hline Govt. Higher Secondary School, Hernoli & 54 & 16.6 \\
\hline Govt. Girls Higher Secondary School Kundian & 55 & 16.9 \\
\hline \multicolumn{3}{|c|}{ Gender } \\
\hline Male & 162 & 49.8 \\
\hline Female & 163 & 50.2 \\
\hline \multicolumn{3}{|c|}{ Tehsil } \\
\hline Mianwali & 111 & 34.2 \\
\hline Piplan & 110 & 33.8 \\
\hline Isa Khel & 104 & 32.0 \\
\hline \multicolumn{3}{|c|}{ Designation } \\
\hline Teachers & 50 & 15.4 \\
\hline Students & s275 & 84.6 \\
\hline \multicolumn{3}{|c|}{ Acad. Qualification } \\
\hline Undergraduate & 275 & 84.6 \\
\hline Postgraduate & 50 & 15.4 \\
\hline \multicolumn{3}{|c|}{ Experience } \\
\hline Not & 274 & 84.3 \\
\hline$(1-5)$ & 16 & 4.9 \\
\hline$(6-10)$ & 23 & 7.1 \\
\hline More than 10 & 12 & 3.7 \\
\hline \multicolumn{3}{|c|}{ Age } \\
\hline Less than 19 & 274 & 84.3 \\
\hline (27 to 30 ) & 25 & 7.7 \\
\hline Over 30 & 26 & 8.0 \\
\hline
\end{tabular}

Table 4.1 signifies the demographical information about higher secondary school of district Mianwali; this study was conduct on 6 higher secondary schools, including 3 tehsil of district Mianwali, 162 male and female in which 50 teachers and 275 students respond. The table also showed that 111 respondent from Mianwali, 110 from Piplan and 104 belong to Isa Khel in which 275 respondent were undergraduate and 50 were postgraduate, 274 had no experience on the other hand 16 had 1-5 years experience, 23 had 6-10 years experience and 12 respondents had more than 10 years experience. This table also signified that 275 respondent were less than 19 years age, 25 were under the 27 to 30 years age and 26 were over 30 years age response to this study.

4.2 Application of One Sample t. test

$\mathrm{H}_{\mathbf{0}} \mathbf{1}$ : There is no significant difference of the mean value of whistleblowing practices with respect to test value 3 Tables 4.4.1 Tables 4.4.1 Mean Value of Whistleblowing Practices

\begin{tabular}{ccccccc}
\hline \multicolumn{7}{c}{ One-Sample Statistics } \\
\hline Variables & $\mathrm{N}$ & Mean & SD & $T$ & df & Sig. (2-tailed) \\
\hline Whistleblowing & 325 & 3.4862 & .74798 & 84.023 & 324 & .000 \\
\hline
\end{tabular}

Table 4.3.1 signified that $\mathrm{t}$ value (84.023) of whistleblowing with respect to test value 3 is significant at $\mathrm{p} \leq$ 0.05 level of significance so our null hypothesis was rejected and it was concluded that there was significant difference of the mean value of whistleblowing with respect to test value (3). The mean score of (3.4864) lies in a good zone.

$\mathbf{H}_{0}$ 2: There is no significant difference of the mean value of religiosity with respect to test value 3 . 
Table 4.4.2 Tables 4.4.2 Mean Value of Religiosity

\begin{tabular}{ccccccc}
\hline \multicolumn{7}{c}{ One-Sample Statistics } \\
\hline & $\mathrm{N}$ & Mean & SD & $t$ & df & Sig. (2-tailed) \\
\hline Religiosity & 325 & 3.4103 & .60188 & 102.145 & 324 & .000 \\
\hline
\end{tabular}

Table 4.3.2 signified that $\mathrm{t}$ value (102.145) of religiosity with respect to test value 3 is significant at $\mathrm{p} \leq$ 0.05 level of significance so our null hypothesis was rejected and it was concluded that there was significant difference of the mean value of religiosity with respect to test value (3). The mean score of (3.4544) lies in a good zone.

$\mathbf{H}_{\mathbf{0}}$ 3: There is no significant difference of the mean value of machiavellianism with respect to test value 3.

Table 4.4.3 Mean Value of Machiavellianism

\begin{tabular}{ccccccc}
\hline \multicolumn{7}{c}{ One-Sample Statistics } \\
\hline Machiavellianism & $\mathrm{N}$ & Mean & SD & $T$ & df & Sig. (2-tailed) \\
\hline
\end{tabular}

Table 4.3.3 signified that t value (91.946) of machiavellianism with respect to test value 3 is significant at $p$ $\leq 0.05$ level of significance so our null hypothesis was rejected and it was concluded that there was significant difference of the mean value of machiavellianism with respect to test value (3). The mean score of (3.4544) lies in a good zone.

\subsection{Application of Pearson Correlation}

$\mathbf{H}_{0}$ 4: There is no relationship between whistleblowing practices, religiosity, and machiavellianism.

Table 4.7.1 Relationship between Whistleblowing Practices, Religiosity, and Machiavellianism

\begin{tabular}{|c|c|c|c|}
\hline Parameters & $\mathrm{N}$ & Correlation & $\mathrm{p}$-value \\
\hline Whistleblowing & 380 & \multirow{2}{*}{$-.026 * *$} & \multirow{2}{*}{.615} \\
\hline Religiosity & 380 & & \\
\hline Whistleblowing & 380 & \multirow{2}{*}{$.031 * *$} & \multirow{2}{*}{.545} \\
\hline Machiavellianism & 380 & & \\
\hline
\end{tabular}

**. Correlation is significant at the 0.01 level (2-tailed).

Table 4.7.1 illustrated that the correlation value $\left(-.026^{* *}\right)$ between whistleblowing practices and religiosity was significant at .01 level of significance on the other hand correlation value $\left(.031^{* *}\right)$ between machiavellianism and whistleblowing practices was also significant at .01 level so our null hypothesis is rejected and it was concluded that there was significant relationship between whistleblowing practices, religiosity and machiavellianism. Correlation values $\left(-.026^{* *}, \& .031^{* *}\right)$ illustrated that this correlation was weak negative correlation between whistleblowing practices and religiosity on the other hand week strong correlation between machiavellianism. It means that whistleblowing practices decreased religiosity, but increased machiavellianism vice versa and significantly correlated with each other.

\subsection{Conclusions}

The purpose of this study was to analyzing whistleblowing practices at higher secondary school level in District Mianwali. The results reflected that is whistleblowing practices highly correlated with higher secondary school level. It was concluded that most of the respondent responded that there was significant difference of the mean value of whistleblowing practices religiosity and machiavellianism with respect to test value (3). It also concluded that relationship between whistleblowing practices, religiosity and machiavellianism. Results also proved our alternate research hypothesis whistleblowing practices had significant and negative impact on religiosity but had significant and positive impact and machiavellianism.

\subsection{Recommendations}

Whistleblowing practices have become a key component in any organizations whether its education institutions or non educational institutes. The following recommendations for future research should be considered: as a result of conducting this study, the following recommendations have been formed: As there is an unmistakable absence of data on whistleblowing (cases, conceivable badgering), gathering data ought to be one of the initial steps. As there are plans to shape and morals chamber for the general population benefit at the Ministry of Finance, some portion of its undertakings could additionally incorporate social affair data, remarking on cases, prompting on exercises and so forth.

More exertion and assets ought to be spent on educating teachers and students in general of instances of whistleblowing and how it can help discovery and examination of defilement. For understanding the contrast between being a nark and an informant, the cases that include an immediate danger to informant or whistleblower are likely generally accommodating initially. 


\section{REFERENCES}

Brown, A., Mazurski, E., \& Olsen, J. (2008).The incidence and Significance of Whistle blowing in A Brown (ED), whistle blowing in Australia Capital Territory, Australia, ANU Press.

Classified and related information disclosure Act. (1998). Retrieved April 30, 2008, from the World Wide Web: http:// www.fas.org/sgp/congress/s1668.htm.

Caslon Analytics guide secrecy and accountability. (2000). Retrieved April 30, 2008, from the World Wide Web: http:// www.cslon.com.am/secresyguide1-.htm.

Dellaportas, S., Gibson, K., Alagiah, R., Hutchinson, M., Leung, P., \& Van Homrigh, D. (2005). Ethics, governance and accountability: A professional perspective. Australia: John Wiley \& Sons, Ltd.

Hills Governance Centre (2004). Whistleblowing in the Philippines Awareness, Attitudes and Structures. Retrieved April 1, 2008, from the World Wide http://www.Aimshills.ph/proejectpage/prs/research3_6htm..

Hannigan, N. S. (2006). Blowing the whistle on health care fraud; should I? Journal of American Academy of nurse practitioners Vol. 18, pp 512-517.

Lewis, N., \& Uys, Z. (2007).Protecting Whistle blowers at work: A Comparison of the Impact of British and South African Legislation. Managerial law, 49 (3), 76-92.

Miceli, M. P., Near, J. P., \& Schwenk, C. R. (1992). Who Blows the Whistle and Why? Industrial and Labor Relations Review, 45(1), 113-130.

Near, J. P., \& Miceli, M. P. (1995). Effective Whistle-Blowing. The Academy of Management Review,20(3), 697-708. Policy and procedures on whistle-blowing: Definition. (1999). Retrieved July, 23, 2007from the World Wide Web: http://www.bhasvic.ac.uk/govenors/Policy\%20File\%20January\%202008/HUMAN\%20RESOURCES/Whis tleblowing_Policy_and_Procedures.pdf.

Ravishankar, L. (2002). Encouraging internal whistle-blowing in organizations. Retrieved September 16, 2007 , from the World Wide Web: http://www.scu.edu/ethics/p;ublications/ submitted/whistleblowing.html.

Rossouw, D. \& Van Vuuren, L. (2004). Organization ethics. (3rd Ed.). Cape Town: Oxford University press Southern Africa.

Sangweni, S. (2005). Parliamentary briefing on the 2005 Annual state of the Public service Report. Retrieved September 17, 2007, from the World Wide Web: http://www..pmg.org.za/ briefings/briefings.php?id=185.

The Protected Disclosure Act, no.26. (2001). South Africa, @2005 Juta and Company, Ltd.

Whistleblowing Act No. 26. (2000). Retrieved October 2, 2007, from the World Wide Web: http://www. Nacf.org.za/guide_to the_whistle_blowing_act/section_two.html. 